\title{
La ciudad como sujeto: formas y procesos de su constitución moderna en Chile, siglos XVIII y XIX ${ }^{1}$
}

\author{
Andrés Núñez ${ }^{2}$
}

\begin{abstract}
RESUMEN
El artículo analiza la formación y consolidación de la representación moderna de la ciudad en Chile. Se plantea que ella, en su lenguaje ilustrado, es un acontecimiento discursivo no comparable con otros imaginarios urbanos y territoriales precedentes, en tanto presenta manifestaciones, procedimientos y significados particulares, todas estructuras de un proceso temporal que hace que ella tenga una historia propia y singular para los siglos XVIII y XIX. Aquí también se propone comprender la ciudad como una forma de racionalidad y como una estrategia de poder y dominio que colaboró sustancialmente en configurar el tipo de orden y sentido territorial que en la actualidad posee Chile. En ello, la ciudad fue, en el fondo, una producción de verdad.
\end{abstract}

Palabras clave: Ciudad, territorio, modernidad, discurso, poder.

\begin{abstract}
This article analyzes the construction and the later consolidation of city's modern representation in Chile. This representation, in its enlightenment language, becomes a lecture event non comparable with other precedent urban and territories imaginaries, in the meantime it shows manifestations, procedures and particular meanings, all these structures of a temporal process, that lets the city to have its own singular history during the 18th and 19th centuries. The paper proposes the understanding of the city as a rationale figure and as a power and domain strategy, which had substantially collaborated in the configuration of Chile`s current order and territorial sense. Given that, the city was, at the end, a production of truth.
\end{abstract}

Key words: City, territory, modernity, speech, power.

El propósito central de este texto es colaborar a comprender que la formación de la ciudad en Chile en su interpretación moderna, es decir, en un sentido ilustrado, es una representación cultural cuyo sentido está dado precisamente por su contexto histórico. Desde esta perspectiva, se plantea que es un acontecimiento discursivo no comparable con otros imaginarios urbanos y territoriales pre-

\footnotetext{
1 Artículo recibido el 8 de marzo de 2010 y aceptado el 30 de marzo de 2010.
}

cedentes, en tanto presenta manifestaciones, procedimientos y significados particulares, todas estructuras de un proceso temporal que hace que ella tenga una historia propia y singular para el Chile de los siglos XVIII y XIX.

El texto se estructura de la siguiente manera: 1) un primer momento en que el territorio en Chile es interpretado desde la

\footnotetext{
2 Doctor en Historia, Pontificia Universidad Católica de Chile (Chile) . E-mail: andresnunezg@gmail.com
} 
perspectiva de la vastedad, la otredad y la heterogeneidad; 2) un segundo instante, más bien de transición, donde la perspectiva, interpretación o representación de la ciudad comienza a constituirse en sujeto $^{3}$; y 3 ), por último, la maduración del ensamblaje de la ciudad que lleva a posicionar el territorio hacia un sentido completamente distinto al de los primeros siglos de colonización.

A partir de este contenido, el interés es llevar el concepto ciudad hacia una perspectiva histórica, con el afán de realizar una suerte de genealogía o búsqueda del origen de la conformación del paisaje urbano que es tan familiar en la actualidad, paisaje que, desde este punto de vista, aún mantiene aquel lenguaje ilustrado a que se hace alusión. En otras palabras, historizar el proceso de configuración del sentido actual o moderno que de ella se tiene y dimensionar, para el caso chileno, el impacto o rol que ella jugó en la definición de una estructura territorial con grados elevados de uniformidad de alcance nacional (siglo XIX).

El presente texto es el resultado de una investigación más amplia en torno a la formación de la representación moderna del territorio en Chile, uno de cuyos ejes principales estuvo marcado por la constitución de la ciudad como sujeto protagónico en el contexto de la definición de estructuras territoriales propias de una época que se comenzó a denominar ilustrada ${ }^{4}$. El interés, por tanto, es detenerse en aquella representación histórica del sujeto ciudad, y cómo, a partir de tal posición, ella se transformó en "discurso verdadero". En otras palabras, se busca identificar aquel proceso histórico, que con su conjunto de reglas, procedimientos y representaciones,

3 Es importante aclarar que lo que se configura como sujeto no es tanto la ciudad en sí como la interpretación que de ella se hace.

4 Se desea manifestar que este trabajo, siendo una investigación histórica, se asienta con mucha fuerza en materias del campo de la geografía, por lo que es claro el interés por proyectarlo o enfocarlo en el ámbito de la Geografía Histórica, una rama del conocimiento muy interesante, aunque sin duda menos trabajada en Chile en comparación al menos a países como México, Argentina o España. derivó en que ella -la ciudad- se volviese una producción de verdad 5 .

\section{Aspectos conceptuales}

Para entender lo anterior de forma más fluida, se cree necesario, a modo de preámbulo, realizar una detención en un aspecto que resulta crucial. Este asunto remite a comprender a la ciudad como un elemento particular que posee una historia también puntual, sin dejar de considerar, evidentemente, su marco temporal del que no puede evadirse. De este modo, historizar la ciudad es escribir y reflexionar sobre un modo de subjetivización, una forma de racionalidad que presenta, por tanto, un carácter de perspectiva temporal. Pero, a la vez, es entender que aquella "posibilidad ciudad" se impone a través de los años en objetivización, en tanto se transforma, precisamente, en objeto real o, como ya se expesó, en discurso verdadero. Como ha expuesto Varela (2002): “... (el objeto real) es la interpretación entendida como la actividad circular que eslabona la acción y el conocimiento, al conocedor y lo conocido, en un círculo indisociable" (Varela, 2002: 90). Se trata, en el fondo, de preguntarse aquí -e intentar responder a esta pregunta- cómo han aparecido tales o cuales objetos posibles de conocimiento y poder, en este caso, la imagen -para el caso chileno- de la ciudad ilustrada (Foucault, 1999).

En este contexto, cuando se habla de sujeto ciudad se hace referencia al momento a través del cual una forma de racionalidad -la ciudad-toma conciencia de sí y se define temporalmente. En otros términos, cuando aquella formación histórica adquiere una identidad propia, tornándose, por tanto, cierta para los espectadores (pasados y actuales). Del mismo modo, para hacerse cargo de parte del título, cuando se habla de modernidad se hace referencia a la instancia cultural que dispuso al hombre como protagonista de la historia y la naturaleza, desligándolo, de esa manera, de la mirada menos ilustrada y

\footnotetext{
5 Cuando se habla de "verdad" se hace referencia al consenso o acuerdo que se da sobre un imaginario o una forma de racionalidad, que en tanto "acuerdo" se vuelve "verdadera".
} 
más cosmológica de los siglos anteriores al XVIII. Más allá de las notables y abundantes discusiones especialmente en el campo de la filosofía sobre la posmodernidad, se asimila acá la modernidad como una disposición o temporalidad aún en curso, en la medida que algunos de sus rasgos más característicos se encuentran todavía presentes en la vida cotidiana, incluida la actual relación del hombre con su medio ambiente. Por lo mismo, se entiende, como ha sido estudiado, más como una actitud, una perspectiva, que una época cerrada de la historia: "Aunque circunscrita hacia fines del XVIII, su rasgo más característico es la actitud y voluntad de heroizar el presente desde la racionalidad" (Foucault, 1991: 197). El paisaje urbano característico de la modernidad, desde este punto de vista, vendría a ser por tanto una actitud de la Ilustración prolongada en el tiempo.

Desde esta perspectiva, la ciudad en el reino de Chile tuvo hacia el siglo XVIII, precisamente a partir de la actitud de la modernidad, cierta historia, ella misma fue un lenguaje del saber, del poder y del conocimiento. De parte de esta historia particular se hace cargo este artículo, es decir, de aquella forma de racionalidad que se configuró de determinada perspectiva a partir de la actitud moderna ${ }^{6}$. En otras palabras, de aquel acontecimiento (la ciudad) que permitió orientar un modo de comprender y representar el territorio como no antes.

Se piensa que en la actualidad una lectura de este tipo es necesaria, especialmente cuando, desde el punto de vista de su objetividad, es indiscutible su rol de actor principal y modelador del territorio en su conjunto. Pero a la vez, parece importante fijar su posición desde la relatividad de la represen- tación, particularmente si se la mira desde el prisma o perspectiva del acontecimiento discursivo histórico. Esto último es relevante, ya que desde este punto de vista, la ciudad no es esencia, en ello se discrepa de Romero (2009), sino más bien se trata de un constructo representacional, una puesta en escena, una disposición epocal ${ }^{7}$. Lo rural y lo urbano han adoptado perspectivas en el tiempo, por lo tanto realidades, a partir de su contexto epocal o histórico.

Ahora bien, y esto es muy importante de comprender, no se trata acá de colocar a la ciudad como original del siglo XVIII y, por lo mismo, establecer que ella es un producto de la modernidad. En la práctica, formas o sentidos urbanos los ha habido, por ejemplo, desde la fundación de Enoc por Caín (Romero, 2009; Chueca, 1997). Lo que se desea expresar, y ese es el interés de este texto, es el hecho de que lo que cambia con la modernidad es la forma de interpretar el espacio, es decir, es la perspectiva la que se modifica haciendo que el discurso ciudad, como su posterior objetivización, se torne no solo real sino inconmensurable con lecturas anteriores de ella. En ello, en el nuevo modo de enfrentar el territorio, la ciudad es, ahora sí, esencial (Núñez, 2009).

En fin, proponerse comprender la ciudad moderna como giro paradigmático; con esto es de interés especificar que el valor que ha tenido a través del tiempo nunca ha sido el mismo. Su sentido ha variado, se ha ido modificando $y$, por tanto, posicionando de acuerdo a cada época. Se parte de la premisa, por tanto, que "cada época de la historia humana produce, a través de sus prácticas sociales cotidianas y su lenguaje, una estructura imaginaria" (Varela, 2006: 11).

\footnotetext{
6 No se habla aquí de racionalidad de modo global, sino de una forma particular de racionalidad que es la formación de un paisaje urbano como elemento constituido de poder y verdad. El conocimiento como perspectiva es uno de los aspectos más relevantes heredados del filósofo alemán F. Nietzsche. Para historiadores y geógrafos históricos resulta muy estimulante tener a la vista su texto Consideraciones intempestivas (Nietzsche, 1988), particularmente el referido al estudio de la Historia.
}

\footnotetext{
7 También de Spengler quien dice "La historia universal es historia ciudadana"; primero, porque trata de remitir a la historia a un solo discurso evolutivo, y segundo, porque establece, tal como lo hace Romero, que la ciudad es el elemento central y sustancial (hilo conductor) de aquella "Historia".
} 


\section{La ciudad en los espacios de la vastedad: diversidad y heterogeneidad territorial ${ }^{8}$}

El territorio preilustrado (antes del siglo $\mathrm{XVIII)}$ estuvo lejos de ser un horizonte uniforme y homogéneo, tal como se visualiza en la actualidad. Por el contrario, desde los inicios de la colonización española fue una estructura muy fragmentada y diversa. Sin duda, en ese marco espacial, los polos urbanos significaron algo y buscaron, tímidamente, articular y dominar el escenario territorial americano. En el caso del reino de Chile, como se verá, aquella articulación se remitió a escasas fundaciones, todas precarias e inestables. De allí que si bien se hablará de ciudad, se comprenderá acá todavía como una estructura que significaba y remitía a un discurso muy distinto al que posteriormente, con la actitud ilustrada, habría de devenir. Desde cierto punto de vista, se cree que el concepto de ciudad como se entiende en el presente, heredero de la forma de racionalidad moderna, no es asimilable a lo que se comprendía por ciudad antes del XVIII y el XIX.

De esta suerte, el imaginario territorial de los siglos XVI, XVII, aunque también buena parte del XVIII, incluso aun parte del XIX (el proceso discursivo fue lento), se remitió a una concepción más bien heterogénea y múltiple del espacio ${ }^{9}$. De esta pluralidad da

8 Estando este texto prácticamente terminado ha sido facilitada una investigación de primer nivel (Muñoz, 2009) sobre la ciudad chilena en la Colonia. Es un trabajo que ha sido presentado como tesis doctoral y que coincide en muchos aspectos con esta investigación y con otro trabajo doctoral (Núñez, 2009) referido a la formación moderna del territorio en Chile. De ese trabajo se ha tomado prestado aquello de "los espacios de la vastedad", ya que refleja de forma muy clara lo que se expone en las siguientes líneas y se acerca nítidamente a los conceptos de diversidad y heterogeneidad usados por esta y otras investigaciones. Se agradece a la autora.

9 Una de las hipótesis de trabajo de la investigación de María Dolores Muñoz es precisamente: la coherencia de las interrelaciones recíprocas entre la ciudad colonial y su entorno estaba relacionada con las diferentes interpretaciones del paisaje, entendidas como las perspectivas culturales desde donde los colonizadores se aproximaron al espacio geográfico que debían dominar. Al hablar de diferentes interpretaciones del paisaje, la autora, como cuenta Téllez (1990) al estudiar el espacio pehuenche y definir que la cordillera de los Andes, lejos de semejar un bloque compacto como es reflejada en la actualidad, "se anarquizaba en una pluralidad de reducidas cordilleras transversales" (Téllez, 1990: 11), representando una geografía complicada y diversa. Abundaban a los ojos de aquellos primeros habitantes, colonizadores incluidos, los valles y pasos intercordilleranos, los típicos ríos torrentosos de la cordillera y, por cierto, la multiplicidad de bosques. Solo en la zona de la pehuenía, del Laja al sur, se han identificado alrededor de 27 pasos que manifiestan la activa comunicación transversal entre grupos de indígenas de ambos lados de la cordillera, definiendo así el sentido del territorio: Buta Mallín, Leña Malal, Picunleo, Trapa-Trapa, Pucón Mahuida, de Rahue, de Pehuenco, de Pino Solo, de Pino Hachado, de Mallín de Icalma, de Icalma, de Llaima, Tres Picos, Pirihueico, entre otros (Ugarte Palma, 1996).

El español a su llegada mantuvo por un buen tiempo una mirada múltiple del territorio, reconociendo lejanías y otredades, variaciones y texturas espaciales, lo que condujo a una imagen amplia y heterogénea de los espacios, algunos de los que, antes desconocidos e incógnitos, poco a poco se fueron incorporando a la representación del territorio colonizado ${ }^{10}$. Así, por ejemplo, hacia fines del siglo XVI, en la década de 1570, el cosmógrafo y cronista Juan López de Velasco (1901) establecía que "las provincias de Chile es lo más apartado y lejos en lo descubierto de las Indias Occidentales..." (López de Velasco, 1901: 295). El escaso conocimiento de esta nueva zona hispánica

\footnotetext{
lo explicita, se remite a los distintos puntos de vista desde donde los nuevos habitantes o colonizadores se explicaban o representaban el paisaje. Aquellas distintas perspectivas se vieron influidas y en parte condicionadas por el avance de las ciencias geográficas, las exploraciones científicas, el perfeccionamiento de las técnicas de medición, entre otras, todo lo cual fue modificando o rectificando las estrategias colonizadoras o influyó en la morfología, funciones y significado de las nuevas ciudades.

10 Respecto del concepto de "otredad" notables son los escritos de Octavio Paz, especialmente El laberinto de la soledad e Inmediaciones, ambos disponibles en numerosas ediciones.
} 
se veía proyectado, a su vez, en el nivel de colonización descrito por el cronista: "El obispado de Santiago, tiene el distrito desde el valle de Copiapó... hasta el río Maule, que parte los términos de la ciudad de Santiago y de la Concepción... Hay solo cuatro ciudades, en que hay seiscientos españoles, y en ellas veinte y cuatro mil indios de tributo..." (López de Velasco, 1901: 295).

La zona sur, vinculada al obispado de Concepción, según carta del gobernador español Martín García Oñez de Loyola al rey, se encontraba hacia fines del siglo XVI en estado de semiabandono, además de carente de recursos. Así, expresaba que "más allá del Maule, que solía ser almacén de bastimentos y pertrechos de guerra por su mucha fertilidad y abundancia de indios, ha venido a tanta disminución y menoscabo, que pasando por ella solo mi casa, estuve detenido cuatro días por no poderme aviar por falta de veinte raciones y seis indios" (Villalobos y Rodríguez, 1997: 107).

La fundación de Chillán o Bartolomé de Gamboa, como se le llamó originalmente, en 1580 no significó conformar un territorio más unitario y solo cumplió el papel básico de asegurar las comunicaciones hacia Concepción y el sur, así como un rol militar, por lo demás objetivo de la mayoría de las villas que se fundaron en el sur durante el siglo XVI y los siglos posteriores ${ }^{11}$. Fray Diego de Oca-

\footnotetext{
${ }^{11}$ El origen de la fundación de ciudades o villas, en el marco del proceso de colonización español, durante los siglos XVI, XVII, XVIII tuvo diversas razones, entre las que se pueden indicar: defensa: la Imperial, Angol, Villarrica y San Mateo de Osorno, Nacimiento y Santa Bárbara; racionalización del espacio y continuidad de los caminos: Santa Cruz de Triana (Rancagua), San Fernando, San Ambrosio de Linares, Santa Luisa de Parral, Santa María de Los Ángeles, entre otras; producción minera: San Ambrosio de Vallenar, San Francisco de la Selva (Copiapó), San Rafael de Rozas (Illapel), entre otros. Es posible también agregar a los roles el de 1) activar el desarrollo agrícola, 2) ampliar el dominio de las áreas rurales, 3) consolidar la ocupación del territorio colonizado al norte del río Biobío, 4) defensa del litoral ante agresiones externas, 5) consolidar la ocupación de zonas marginales del proceso de colonización, entre otras. Para un análisis detallado de estas funciones como de la posición de la ciudad en el territorio de colonización para los siglos indicados, el trabajo doctoral ya mencionado de María Dolores Muñoz (2009) es clave e indispensable.
}

ña, al finalizar el siglo XVI, apuntaba: "esta ciudad es pequeña, no tiene más de cincuenta vecinos, y no sirve más de albergue de los pasajeros que van a las ciudades de arriba..." (Villalobos y Rodríguez, 1997: 107)12. Por cierto, el panorama se tornó aún más desolador con posterioridad a la rebelión indígena de 1598. El proceso ulterior se vincula, por tanto, a una nueva colonización, asociada sobre todo a oficiales del ejército que buscaban allí nuevas oportunidades para su vida. Como bien expresan Villalobos y Rodríguez (1997), el escaso interés por colonizar y la pobreza local se mantuvieron en la medida en que el espacio quedó ligado a los vaivenes de la frontera bélica de la zona de la Araucanía.

Más al norte, en el área comprendida entre los ríos Maule y Maipo, la organización espacial en el siglo XVII mantuvo la discontinuidad y fragmentación manifestada en la zona fronteriza. Hacia 1657, un informe de Alonso de Solorzano y Velasco muestra que Chillán aún permanecía en condición inestable, con una ocupación notablemente precaria. En este marco, el oidor español proponía otorgar mayor importancia para la colonización al espacio ubicado más al norte del río Maule: “...convendrá despoblar la ciudad de la Concepción dejándola fortificada con solo 200 soldados haciendo mejor y más segura mención que ya se vieron despobladas en otra ocasión las ciudades de la Imperial, Villa-Rica y Angol, Osorno y ahora la de ChiIlán y pasar sus armas a el partido de la rivera de Maule, poblando en Duao, país capaz de buen temple y muy fértiles en aquellas riberas donde se resguardara el vado que el río abre allí, tiene gran comodidad para el riego de sus tierras, todos los que tienen estancias desde el río Maipo hasta el río Maule que son 36 a una a dos a tres y más leguas de estancias se les puede reformar dejándoles las tierras necesarias y otro tanto más y en lo restante acomodar a los pobladores con que quedaran unos con otros abrigados, la tierra poblada y

\footnotetext{
12 El término de "arriba" es interesante, ya que en la actualidad el sur se vincula con una percepción contraria, es decir, "más abajo", considerando que el eje geográfico del territorio está configurado de "norte a sur". Por el contrario, lejos de este esquema mental, las tierras ubicadas "al sur" del asentamiento de Chillán estaban identificadas con zonas ubicadas espacialmente hablando "más arriba".
} 
rica, impedida la entrada a el enemigo por la cordillera y demás pasos..." (Gay, 1840: 443).

Del informe es posible inferir la real posibilidad de redistribuir la tierra, lo que permite observar importantes espacios vacíos, propios de territorios discontinuos y de colonización frágil. La inseguridad en la conformación de núcleos de población que actuasen como referentes territoriales, sin duda influido por los levantamientos indígenas de 1654, llevó a pensar al citado oidor que un área de mayor concentración podía llegar a establecerse en la zona costera de la actual Región del Maule. De hecho, la refundación de Chillán en 1663, junto a la promesa de un compromiso mayor de parte de la Corona española con los colonos, inició un período lento de reorganización espacial: "Volver a ocupar la región fue una tarea lenta y arraigada, que tomó varias décadas a partir de 1655..." (ViIlalobos y Rodríguez, 1997: 111).

Lo anterior, es decir, la complejidad para ocupar y organizar estos territorios, afianzó un proceso muy interesante, que tuvo que ver con un reforzamiento del poblamiento del valle central, particularmente de la zona en torno a Santiago, en la medida que ella apareció ante los ojos de la mayoría de los habitantes del reino como el área ideal para vivir y asentarse.

Si durante el siglo XVI los asentamientos del sur, próximos al río Biobío y relativamente cercanos unos de otros, constituyeron un Ilamativo polo de desarrollo, "a partir de 1600, Santiago consolida su puesto como la primera ciudad del país" (Guarda, 1978: 54), afianzando ya en aquella lejana época el centro de gravedad en torno al eje SantiagoValparaíso-Aconcagua. Un interesante dato permite confirmar lo expuesto: la zona en torno al núcleo de Valdivia dependió administrativamente del virrey del Perú en forma directa hasta bien entrado el siglo XVIII, 1740, en que solo por cédula del 17 de septiembre fue encargada a la Capitanía General de Chile. A pesar de ello, parte importante de esta zona austral mantuvo un estatus especial respecto de los gobernadores, limitando sus intervenciones (Guarda, 1979).

Es decir, junto a una diferenciación clara entre el valle del río Maipo y la zona austral, esto es, más allá del Maule, parte de aquella área geográfica no perteneció administrativamente al gobierno instalado precisamente en la ciudad de Santiago. Como se verá, la representación espacial en el seiscientos y setecientos fue el reflejo de una contradicción entre la estructura urbana del Chile colonial, si es posible Ilamarla de esa forma, donde el límite entre lo rural y lo urbano se manifestaba de manera muy difusa, y ciertas formas heredadas del medievo europeo, con una trama compleja de jerarquización y disposición del espacio, donde la ciudad jugaba un rol protagónico ${ }^{13}$. Tal contraste, en cierto modo, Ileva a fijar para el siglo XVII chileno una atemporalidad territorial, en tanto que la vida del colono se insertó y desarrolló en un espacio geográfico y cultural diverso, incluso de rasgos antagónicos entre sí (Trebbi del Trevigiano, 1980; Bayon, 1974) ${ }^{14}$.

Desde esta perspectiva, para este tiempo hablar de estructura urbana, como lo hacen Guarda (1978) y otros autores, tal vez, resulte una exageración. Hacia 1610 solo cinco asentamientos podían llegar a poseer un sentido urbano un poco más delimitado (con la relatividad indicada para el término). Aun así, y por mucho tiempo más, no constituyeron más que aldeas o villorrios en los que la vida transcurría con grados importantes de la atemporalidad indicada para el resto del vasto territorio. Esos centros eran La Serena, Santiago, Chillán, Concepción y Castro (Figura $N^{\circ} 1$ ). En todas ellas, la estructura urbana

\footnotetext{
13 Dice Trebbi del Trevigiano (1980) que "España era un país urbanísticamente medieval al producirse la conquista" (Trebbi, 1980: 23), para referirse a la composición de una compleja estructura jerárquica, cualitativa tanto en lo urbano como en lo rural. En el mismo sentido, y para clarificar la diferencia entre los sentidos urbanos heredados del medievo europeo y la difusa estructura urbana del reino de Chile, Pirenne (1980) reafirma aquella posición urbana de mayor relevancia: "... la ciudad medieval, tal y como aparece en el siglo XII, es una comuna que, al abrigo de un recinto fortificado, vive del comercio y de la industria y disfruta de un derecho, de una administración y de una jurisprudencia excepcionales que la convierten en una personalidad colectiva privilegiada" (Pirenne, 1980: 138).

${ }^{14}$ La temporalidad, en un sentido evolutivo (siglos XVIII y XIX), herencia del cristianismo, es decir, dirigida hacia un fin, es uno de los rasgos más distintivos de la racionalización moderna de la vida.
} 
no superaba las setenta casas, con la excepción de Santiago que ya alcanzaba más de doscientas (Amunátegui, 1937). Con todo, los referentes urbanos más relevantes los constituían los conventos y las iglesias, lo que refleja la existencia de una sociedad poco secularizada, carencia que por cierto tuvo sus efectos en la relación del español con el territorio: "El lujo de la metrópoli fundada por Valdivia (Santiago) consistía en sus iglesias. A más de la Catedral, se habían construido templos en los conventos de Santo Domingo, San Francisco, La Merced, San Agustín y la Com- pañía de Jesús. Había también dos monasterios de monjas..." (Amunátegui, 1937: 53).

Como es fácil de comprender, Castro no era más que una pequeña aldea con solo 12 ranchos, además de encontrarse hasta el presente aislada por tierra. Concepción constituía un enclave fronterizo y Chillán estaba mayormente constituida por habitaciones de paja, denominadas ranchos. Particularmente importante es la posición de La Serena, otrora centro de mayor relevancia al ser un centro forzoso de retorno al virreinato del Perú, ya

Figura $\mathrm{N}^{\mathrm{o}} 1$

Ciudades a fines del siglo XVII
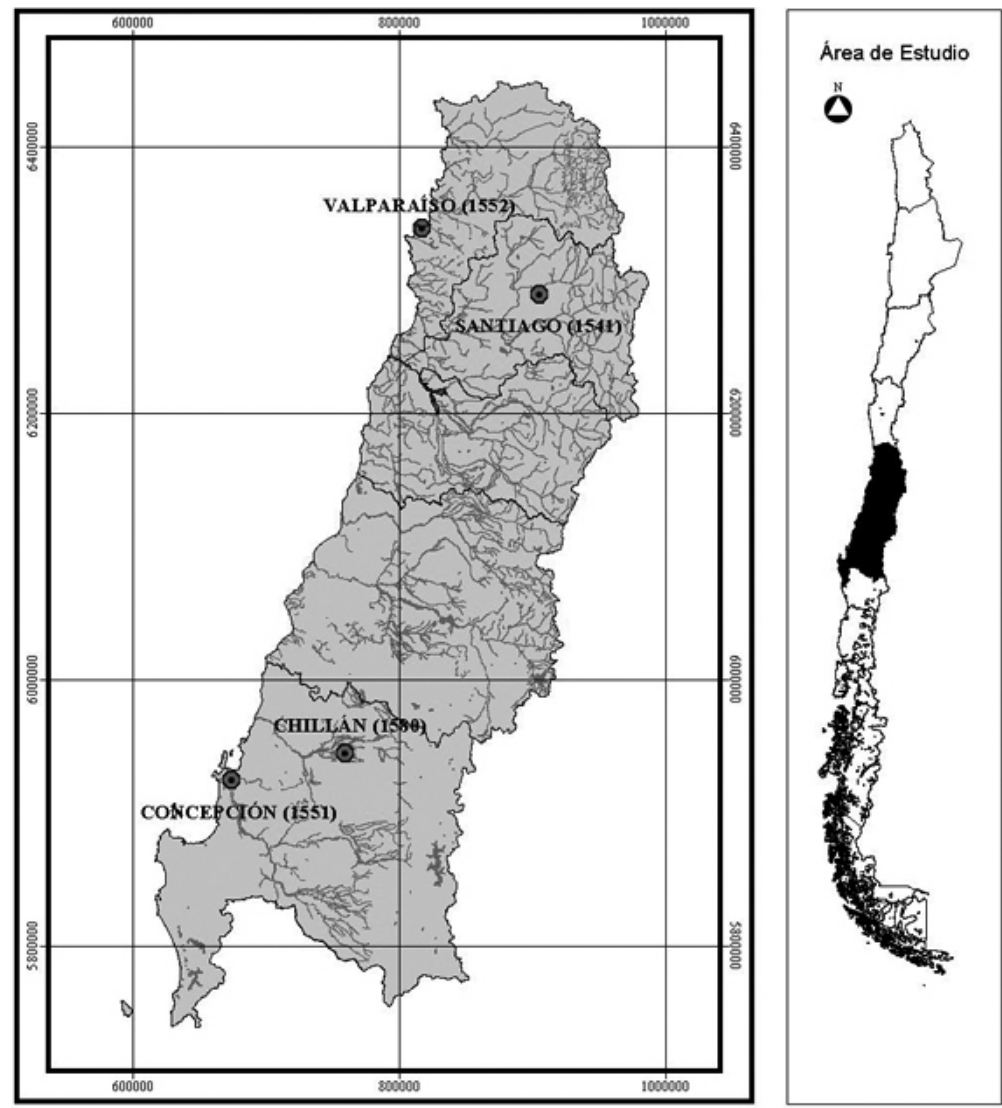

100

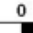

100

$200 \mathrm{~km}$ 
que con el descubrimiento hecho por el piloto Juan Fernández, en 1574, los comerciantes y soldados, tanto en el viaje de ida como de regreso, preferían la vía marítima, que era más rápida y segura. Para evitar la corriente marina adversa, les bastaba alejarse de la costa hasta la latitud de Valparaíso. De este modo, La Serena, durante todo el siglo XVII y parte del XVIII, se mantuvo aislada (Amunátegui, 1937).

A esta estructura urbana, el oidor de la Real Audiencia, Gabriel de Celada, agregaba otros tres centros, todos en el lado oriental de la cordillera de los Andes, en la provincia de Cuyo: San Juan, La Punta y Mendoza. El mismo relator concluía frente al rey que todas estas poblaciones "son tan pobres como poco pobladas" (Gay, 1840: 95). En forma inequívoca, la posición oriental de ellas hizo fijar las miradas del habitante del valle central en un horizonte que traspasaba la cordillera de los Andes, incorporando aquellos territorios a su imaginario, reforzando la representación horizontal del espacio, en un sentido orienteponiente o viceversa.

Lo expresado con anterioridad no inhibe para el siglo XVI y XVII el rol que jugaron villas o zonas donde se produjo mayor concentración de población. La ciudad, en general, fue el núcleo importante de poblamiento y desde donde, en cierto modo, se organizó el territorio. De hecho, el territorio quedó originalmente articulado en doce circunscripciones, incluida Cuyo, sustentadas solo por una ciudad principal, de las cuales rápidamente se extinguieron seis ${ }^{15}$ (Cobos, 1989). Sin embargo, a pesar de ese rol aglutinador inicial, en la práctica, todas o la mayoría de las ciudades de estos siglos de colonización inicial se mantuvieron por años a la deriva, sobrellevando una vida precaria y erizada de dificultades. Podría más bien

\footnotetext{
15 Las ciudades iniciales eran La Serena, Mendoza, Santiago, Chillán, Concepción, Angol, Cañete, Imperial, Villarrica, Valdivia, Osorno y Castro, aunque estas últimas cumplían más bien un rol de defensa. Al iniciarse el siglo XVI los asentamientos de la zona austral se extinguen, fruto de su propia precariedad como de la resistencia indígena.
}

decirse que fueron enclaves en despoblado (Cobos, 1989).

A tal escenario, en el siglo XVII debe anexarse la posición que adoptan estos enclaves respecto de su entorno. No existió, en definitiva, una delimitación clara respecto a los habitantes que "hacen vida urbana normalmente, y los que se van asentando ordinariamente en el territorio" (Góngora, 1971: 3). En un proceso natural, el español se fue desenvolviendo en el espacio rural. Así, por ejemplo, en el valle de Quillota, junto al camino Santiago-Valparaíso, hay suficientes pequeños y grandes propietarios en torno a un convento franciscano para que en 1629 se establezca allí una escribanía; de este modo, los vecinos de estas localidades ya no necesitan ir a la capital para sus escrituras públicas (Góngora, 1971).

Tal difuso límite entre ciudad y zona rural, particularmente tenue y frágil en el siglo XVII, desde esta perspectiva, obedece a que la noción del espacio era en su base percibida de esa forma, es decir, conformada por una imagen espacial amplia y, en el fondo, heterogénea, desarticulada y poco compacta. En cierto modo, se trataba, si se desea mantener la palabra ciudad, de una ciudad abierta sobre el territorio.

Tal grado de dispersión rural, como han observado De Ramón (1978), Góngora (1971) y otros, se produjo de la mano de un nuevo estilo en la actividad productora del país, que pasó de poner atención a la búsqueda de oro a una preocupación mayor por la actividad agropecuaria. Esta "fomentó la difusión de la vida rural entre los descendientes de los españoles dispersando así la población" (Solano y Cerrillos, 1990: 464). Este tipo de organización u ordenamiento del espacio físico y social fue extensivo al resto de América Latina, aun cuando hubo centros urbanos que por un sistema de comunicación más compacto articularon de forma más racional el espacio regional y local (Céspedes del Castillo, 2000). Sin embargo, para el caso chileno en particular no se logró una articulación con la red general de tráficos o aquello se consiguió de un modo parcial y precario, debido, entre otras razones, a la escasez de población, aislamiento geográfico y marginalidad en la producción y vinculación 
mercantil frágil y modesta. Estos espacios con sus economías y modos de vida pueden llamarse zonas desarticuladas y que prolongaron la mirada territorial y cultural de los primeros tiempos con su misma aspiración a la diversificación y autosuficiencia y con idéntica estructura: una minoría de colonos en asentamientos pequeños y pobres, o incluso en zonas rurales para mejor explotar los excedentes de producción de comunidades indígenas, con un arraigo espacial de tipo fronterizo permanente (Céspedes del Castillo, 2000).

La imagen que se generó con la apropiación del espacio rural fue expuesta en los variados informes de los gobernadores y oficiales reales. En aquel panorama era posible ver a pastores, vaqueros y arrieros distribuidos por los hacendados en puntos clave del interior de sus tierras: en los límites, las rinconadas de invernada, las pequeñas pampas por donde el ganado pasaba en diferentes épocas del año. De este modo, el paisaje característico del campo chileno del siglo XVII estuvo íntimamente relacionado con grandes territorios abiertos, territorios cuyo ritmo tenía que ver con los impuestos por un tipo de desarroIlo endógeno, vinculado a la atemporalidad a que se hizo alusión anteriormente: "Muy modestas casas de administradores, graneros y corrales, los trabajadores y habitantes de la hacienda repartidos en grupos de dos o tres ranchos distantes unos de otros y a veces en increíbles lugares dentro de la misma hacienda. El viajero caminaba leguas para encontrar un par de ranchos y así se repetía el paisaje en jornadas de días enteros" (Mellafe, 1975: 133).

Indudablemente, esta disposición respecto del territorio, la ciudad abierta, amplió el radio de influencia de la capital, valorizando el área comprendida en torno al río Maule. Ello llevó por tanto a una mayor presencia colonizadora sobre esa zona, planteando de ese modo un nuevo papel tanto para las comunidades indígenas como para los pasos cordilleranos. Así lo ha expresado Góngora, al plantear que la organización de la propiedad del suelo rural es un fenómeno del siglo XVII y que, entre sus efectos, lejos de concentrar población y organizar racionalmente el espacio, tendió a una formación de estancias de tipo amplio, tratando de coincidir con las líneas del relieve y de la hidrografía. En esta medida, como expresa el propio Góngora (1970), "la tierra tiene todavía un valor incipiente, muy inferior al que se le adherirá en los dos siglos siguientes (XVIII y XIX)" (Góngora, 1970: 118).

Una muestra más de la ruralización del territorio, es decir, un espacio urbano que se perdía en la amplitud del espacio rural, estuvo dada por la instauración de partidos rurales, sin sede permanente de autoridades. En este período surge la figura del corregidor que en todos los casos vivía en el asentamiento principal de las amplias zonas o, derechamente, en Santiago. En la práctica, este personaje fue más bien simbólico, en la medida que la población vivía completamente repartida y sembrada en sus campañas y parajes, en rancheríos, haciendas, casas y la costa (marina), de modo que se hizo imposible que un solo corregidor ejerciese el control sobre el territorio: "Las distancias por cubrir entre las localidades de asentamiento eran apreciables, las travesías fragosas y arriesgadas; y todo esfuerzo venía en duplicarse cuando la mayor parte del año debía de transitar, obligadamente, por caminos hechos unos lodazales y cruzar sinnúmero de ríos y esteros, y esteros más peligrosos que los mismos ríos, todos con doble régimen de caudal -pluvial y nivoso- e invadeables en período de crecidas, y con el agravante de que vastas porciones de tierra quedaban convertidas en islas, al perderse vados y pasajes con las corrientes y turbiones" (Cobos, 1989: 26).

Interesa recalcar que tal dispersión implicó una pauta simbólica hacia el territorio y, en esa medida, hizo surgir valores y costumbres en el modo de accionar hacia él. Desde el punto de vista aquí tratado, el valor ciudad en este contexto temporal implicó un acontecimiento discursivo tan arraigado como lo fue posteriormente la consolidación de la ciudad ilustrada, matriz de una interpretación espacial marcada por la integración y homologación territorial. En este hecho discursivo -la racionalización e integración territorial- la ciudad jugó un papel protagónico. La diferencia de ese valor y perspectiva, se estima, estuvo dada en el énfasis de su rol en los primeros años de colonización respecto de los siglos posteriores. 
El espacio rural al adquirir una dimensión distinta a toda otra previamente conocida, llevó a valorizar áreas que antes no poseían importancia alguna y, en cierto modo, levantó íconos territoriales, como ríos, valles, espacios costeros, accesos transversales como, por ejemplo, el río Maule y toda su zona de influencia, que pasaron a ser actores relevantes del, aunque paulatino, nuevo modo de relación del hombre con el espacio. Desde cierta óptica, esta nueva valorización y disposición hacia el suelo forjó un sistema cultural que llevó a desligarse de formas de uso previo y que, sobre todo, poco o nada tuvo que ver con el que se fue instaurando paulatinamente a partir del siglo XVIII.

En resumen, siguiendo nuestro hilo argumental del presente artículo, el siglo XVII en su conjunto asiste a una prolongación de lo urbano, si es posible Ilamarlo así, en la posición de ciudad abierta al territorio. El eje estructurante inicial, lo urbano-militar, es reemplazado por un nuevo centro de gravitación marcadamente rural. En la práctica, durante todo el siglo en cuestión no se fundó ninguna ciudad de importancia en contraste con la ocupación inicial y la política fundacional posterior (Mellafe, 1981).

El punto es clave para el propósito planteado aquí, ya que el modelo inicial urbanomilitar, cuyos íconos es posible visualizar para el siglo XVI en Santiago, Concepción y algunos asentamientos menores de zonas australes, se transformó hacia el siglo XVIII en un modelo que volvió a posicionar lo urbano como eje estructurante del espacio, pero desde una posición radicalmente distinta a la inicial. Este giro paradigmático surge con el siglo XVIII, específicamente con la llegada del modelo francés (borbones), donde lo urbano tendió a una postura mucho más racional, propia de los tiempos, en que la ciudad fue vista como ente administrativo, regulador del tráfico comercial y punto de enlace de la compleja trama de relaciones sociales y económicas, además de reflejo del depósito de ideas que las colocaban como punta de lanza en el devenir temporal de los hombres. Es decir, allí se conjugaba la historia.

Aquel nuevo rol, ahora más civil que militar, forma parte del inicio de la confor- mación del nuevo acontecimiento discursivo, este es el proceso de unificación territorial, necesario para administrar y controlar el territorio en su conjunto, dando pauta, como ya se ha insinuado, a los procesos de racionalización, control, dominio y ordenación territorial que darán origen a la representación del espacio en el siglo XIX: "La ciudad militar, prototipo de la establecida en el siglo XVI, dejó sitio a la civil, modelada por Santiago durante el siglo XVII y adoptada definitivamente para todas las nuevas poblaciones de la zona central del país que surgieron durante el siglo XVIII (Quillota, San Felipe, Los Ángeles, Talca, Cauquenes, San Fernando, Curicó, entre otras). Justamente la repoblación de Concepción en otro lugar de aquel que tuvo originalmente y las incidencias ocurridas con motivo de su traslado en la segunda mitad del siglo XVIII, constituyen todo un símbolo del cambio y son síntomas claros de la modificación del concepto de lo urbano que se había producido en el país" (De Ramón, 1978: 188).

En contraste, con un valor o perspectiva muy distinta, a principios del siglo XVII un testigo de la época afirmaba que Santiago era la única ciudad del vasto territorio, estimando que "ya no hay más Chile" (De Ramón, 1990: 33) ${ }^{16}$. El resto del territorio vivía de su amplitud y del sentido desarticulado que aquella misma amplitud imponía. De esta suerte, los asentamientos, precarios y frágiles se dispersaban por el territorio ostentando un nombre más que materializando la necesidad de control: "... porque entiendo que la ostentación de alguno de sus fundadores, por la fama que tenían sus obras con tal nombre de ciudades, o por pensar que con el tiempo vendrían a ser populosas, obligó a darles desde el inicio tal nombre como en confianza, cuyo origen de nombre de ciudad lo fundan en las más en un fuerte de poca consideración de palos o tapia donde desde el nacer, las bautizan con tal nombre; y como todas no han crecido de acuerdo a sus edades,

\footnotetext{
16 En el citado texto no se hace referencia a quién es aquel testigo, pero es muy probable que se refiera a Alonso González de Nájera, autor de Desengaño y reparo de la guerra del reino de Chile, quien vivió en la época y que es citado con antelación en el mismo ensayo.
} 
hanse quedado algunas desmembradas como plantas en ruin terreno..." (De Ramón, 1990: $32)^{17}$.

En la misma línea, en general, para los siglos XVI, XVII y parte del XVIII, no es posible hablar de obras públicas en el sentido dado para una parte de este último $y$, fundamentalmente para el XIX, donde se dieron de un modo más sistemático y con una orientación más racional. En la práctica, ellas no existieron. Los caminos, por ejemplo, no fueron objeto de obras especiales, en la medida que

\footnotetext{
17 Así, por ejemplo, en la misma línea, el rey, a través de la Real cédula dirigida a la Audiencia de Chile (Madrid, 11 de octubre de 1608), pedía a la Audiencia de Chile explicación por la despoblamiento de la provincia de Cuyo, expresando el asunto del siguiente modo: "He sido informado que las ciudades de Mendoza, San Juan de la Frontera y San Luis de este distrito se van despoblando porque los vecinos encomenderos de ellas las desamparan y se van a vivir a la ciudad de Santiago y de La Serena, con licencia que sacan para ello de los gobernadores de ese reino por inteligencias y negociaciones que tienen, sacando los indios de los términos de las dichas ciudades se van arruinando y despoblando, que es de mucho inconveniente, especialmente la dicha ciudad de Mendoza, por ser la escala de lo que entra y sale en esas provincias y donde se reparan los socorros de la gente que se envía de estos reinos...." (Jara, 1965: 217). Un texto similar en Medina (1928).
}

constituyeron rutas naturales marcadas más por el tránsito que por trabajos realizados en ellos. La única obra pública de importancia construida en los siglos XVI y XVII, por lo demás reconstruida varias veces, fue un puente colgante que permitía cruzar el río Maipo. No existió otro puente en las zonas rurales hasta fines del siglo XVIII, por lo que en épocas de crecidas, los viajeros que iban al sur -en su mayoría por asuntos militares o eclesiásticosoptaban por la ruta de la costa donde los ríos permitían vado natural o, en su defecto, en balsas (Solano y Cerrillos, 1990). De aquella fragilidad da cuenta la Figura $N^{\circ} 2$.

El panorama invita, por tanto, a preguntarse ¿qué era lo que representaba a Chile en el seiscientos y setecientos?, ¿qué era lo que representaba lo urbano en aquella heterogeneidad y amplitud espacial?, y al observar con detención las palabras de aquel cronista que establecía que además de Santiago "ya no hay más Chile".

\section{Un relativo desarrollo urbano}

El siglo XVIII introdujo cambios indiscutibles en muchos ámbitos, y en consecuencia el discurso sobre lo urbano se fue volviendo cada vez más verdadero, lo que comenzó a afectar directamente en la representación territorial del reino. Una mayor racionalización

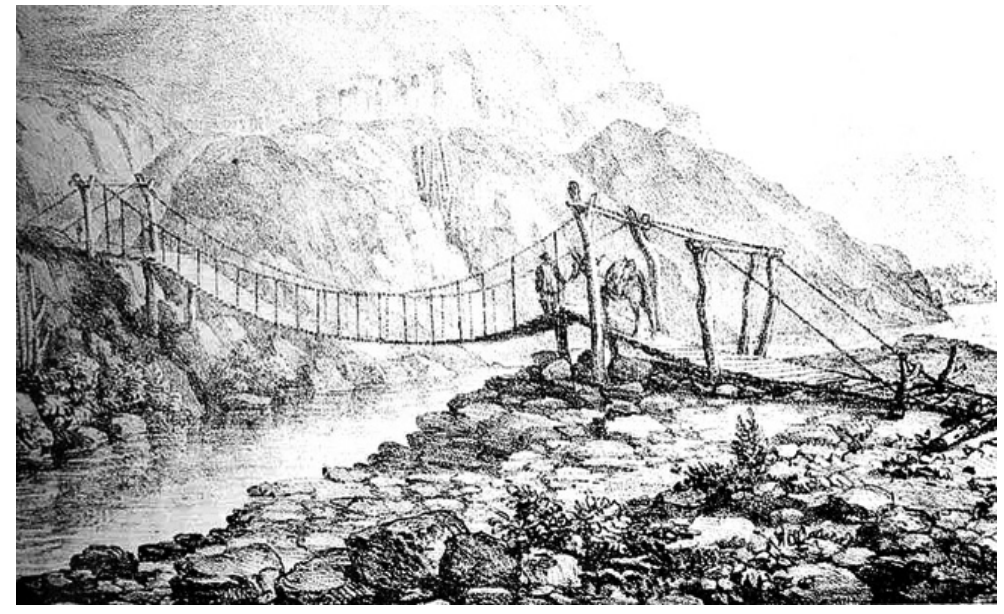

Fuente: González, 1992. 
en las disposiciones espaciales llevó a que la identidad territorial viviese un proceso de cambio que terminó por generar una imagen territorial moderna no comparable ni medible con las anteriores. Este cambio, sin embargo, siendo constante, fue paulatino y demoró todavía al nuevo siglo -el XIX- para afianzar definitivamente la imagen moderna del territorio que en la actualidad se posee $y$, con ella, la maduración de la ciudad ilustrada.

Con la llegada de los borbones se dio curso a una política ilustrada que incidió en el modelo de ordenamiento del territorio colonial y que se concentró en una serie de medidas de control y dominio que impactaron sobre ese espacio en su conjunto, cuyo lenguaje fue llevando a una reinterpretación y a la formación de un nuevo punto de vista y perspectiva del territorio.

Un aspecto que ha sido bastante estudiado $y$, en propia opinión, se le ha sobrevalorado, fue el tema del desarrollo urbano y la fundación de ciudades. Sin duda, se trató de una estrategia pública importante, ya que supuso una actitud de control sobre el espacio que al hombre ilustrado le tocaba administrar. En otras palabras, el proceso fundacional desarrollado por la casa de los borbones durante el siglo XVIII significó bajo esta política urbana una reagrupación territorial que afectó la estructura rural dispersa que hasta inicios de esa centuria presentaba el paisaje del reino.

En efecto, clave en esta nueva disposición territorial fue la renovada valorización de lo urbano como eje de desarrollo territorial, un impacto simbólico de gran relevancia. Sin embargo, como otras líneas de acción, en la práctica, el territorio hacia fines del siglo XVIII e incluso hasta bien avanzado el siglo XIX siguió desenvolviéndose en su amplitud rural. Ya se verá esta disociación importante entre discurso y práctica, es decir, el énfasis por el control y dominio cuyos resultados evidentes desde el punto de vista de la identidad territorial solo maduraron en el siglo XIX.

La formulación común al proceso fundacional del siglo XVIII en Chile, como es el caso de San Agustín de Talca (1742), San José de Buena Vista de Curicó (1743), Santa Cruz de Triana (Rancagua,1743), San Fernando de Tinguiririca (1742), Nuestra Señora de Las
Mercedes de Cauquenes (1742), Santa María de Los Ángeles (1742), por nombrar algunas villas, fue una respuesta directa, entre otros aspectos, a los intereses reales por reforzar su poder -civil y militar - en las zonas rurales del reino, y mantener un dominio práctico y efectivo sobre la población, el territorio y las actividades militares, religiosas y económicas desarrolladas en él. Por tal motivo, en 1703, recién asumida la casa de los borbones, se dictó una real cédula para incentivar una mayor concentración de la población, la que desde la perspectiva de esta nueva dinastía estaba excesivamente ruralizada y dispersa. En cierto modo, el proceso urbanizador, además de haber sido sinónimo de progreso y adelanto, fue una necesidad obvia dado los nuevos sucesos que acontecían en pleno siglo XVIII, como por ejemplo, la reordenación administrativa llevada a cabo por los borbones, así como la serie de prácticas de exploración, viajes científicos y estudio territorial, todo lo cual llevó a adoptar medidas sobre el paisaje rural, entre otros factores, por el problema asociado al latifundio.

El latifundio, como ha quedado demostrado por diversos autores (Mellafe, 1981; Salazar, 1985; Góngora, 1960; Góngora, 1955), terminó al cabo de un siglo por absorber a la gran mayoría de la población rural -"del modo puertas adentro otorgando al reino un particular paisaje humano" (Mellafe, 1981: 96). Su dominio fue amplio y no solo se ejerció en un sentido demográfico y económico general, sino también se extendió al aspecto de la distribución espacial, de la estructura social y de la psicología y valores del campesino (Mellafe, 1981). Durante buena parte de la Colonia, "la hacienda Ilevó una existencia semiaislada. Constituyó un pequeño mundo, alejado de las ciudades y con escasos contactos hacia fuera. Dentro de ellas se producían alimentos, y rústicos bienes artesanales que satisfacían las necesidades de sus habitantes" (Villalobos et al., 1985: 160).

Es decir, la hacienda fue la unidad administrativa que caracterizó el paisaje rural de gran parte de la Colonia, y que concitó la convergencia del poder económico y social del espacio circundante, lo que en definitiva la llevó, entre otros aspectos, a organizar y controlar el comportamiento de la mano de obra, a secundar a la autoridad gubernamen- 
tal en diversas materias, como por ejemplo el control policial, y a habilitar con diversos insumos a las pequeñas unidades productivas de ella dependientes. Desde esta perspectiva, es posible afirmar que la política de poblaciones de la primera mitad del siglo XVIII implicó una revisión y una crítica al sistema tradicional de asentamiento rural y a la gran propiedad (Góngora, 1960).

En consecuencia, la política urbana propiciada por la Corona, "transcurre en un clima de tensiones cuya principal manifestación la constituyen los pleitos en que se ven envueltos los hacendados y los pobladores de las nuevas villas" (Lorenzo y Urbina, 1978: 38). Aquella estrategia urbana solo adquirió mayor consistencia hacia 1740 , con la pre- sencia del gobernador Manso de Velasco, que emprendió precisamente la organización de los espacios urbanos, con la fundación de un grupo de villas en lugares adecuados desde el punto de vista geográfico-político y de la concurrencia de una población base capaz de dar vida propia a las futuras villas (Tscherebilo, 1976). Así, se fundan Los Ángeles, en 1739, y villa de San Felipe, en 1740. Dos años después emergen Cauquenes, San Fernando y Talca; en 1743 se erige Rancagua y Curicó y, finalmente, en 1745 se oficializa Copiapó como villa.

En forma particular, la Figura $N^{0} 3$, referida a la villa de San Carlos, muestra el contexto ruralizado de la ciudad. La preocupación por expresar los accidentes geográficos y los ani-

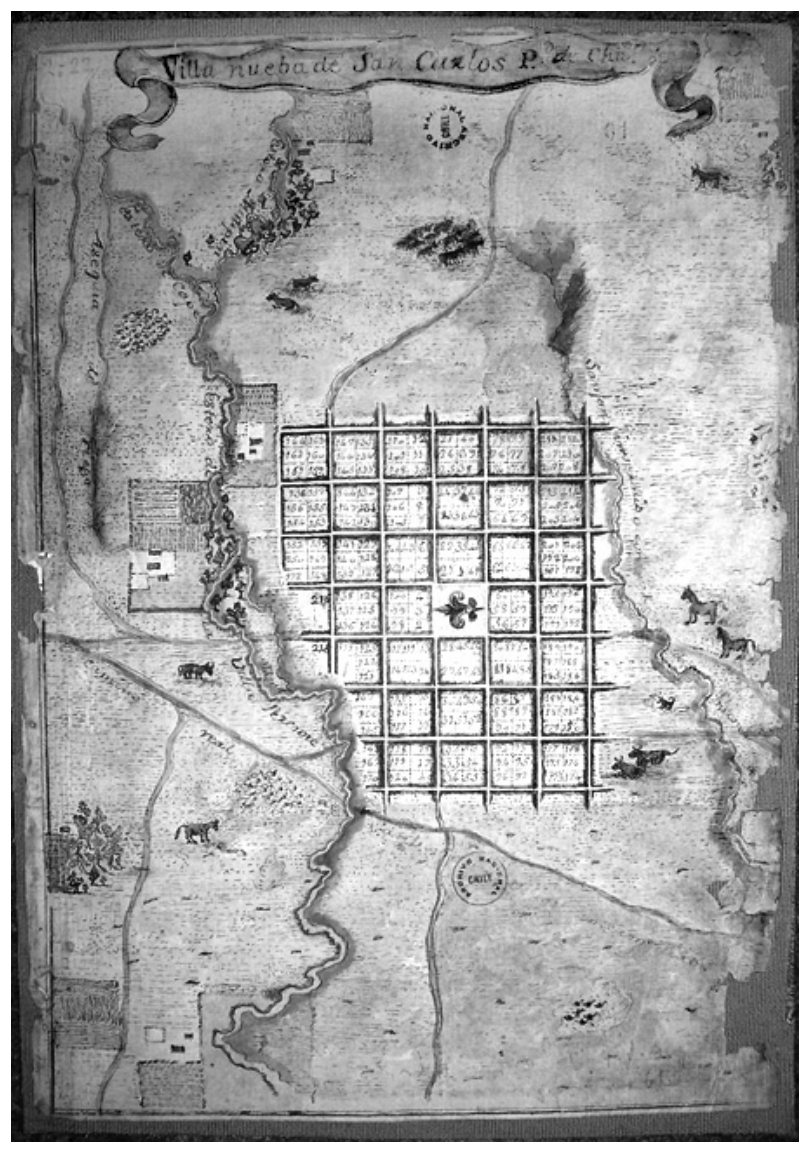

Fuente: Archivo Nacional. Fondo Varios, vol. 969. 
males que la circundan simbolizan la delgada línea entre campo y ciudad, aún para fines del siglo XVIII y comienzos del XIX. Las haciendas en los distintos partidos continuaron, sin embargo, concentrando la mayor parte del poder comercial y cultural, "salvo Quillota y Talca, donde el volumen del comercio urbano fue mayor que en el resto del partido" (Lorenzo, 1987: 103). Expresado de otra forma, el resultado inicial limitado del plan de fundaciones sufrió el impacto de la ausencia de una base económica capaz de originar una estructura ocupacional que asentara en forma estable a los moradores en las villas de reciente creación, de suerte que después de casi 70 años de su fundación, en 1813, Curicó y Talca, por ejemplo, solo alcanzaban los 2.007 y 5.112 habitantes, respectivamente ${ }^{18}$.

La población rural, por tanto, continuó siendo ampliamente mayoritaria durante todo el siglo XVIII, situación que se prolongó en gran parte del XIX, a pesar del programa gubernamental de fundación de villas y aldeas y continuó ubicándose en los campos y en las nuevas franjas fértiles del valle central (Trebbi del Trevigiano, 1980). Llama la atención que entre los criterios recurrentes para emplazar las villas, además de que el terreno tuviese suficiente agua, fuese fértil, dispusiese de árboles para leña y construcción, es que "ellas estuviesen a la vera de los caminos reales" (Lorenzo, 1987). Esto parece importante, ya que la política oficial, tendiente a la centralización de la población dispersa, terminó por otorgar un mayor sentido y protagonismo al camino o sendero del valle central, afianzando una ocupación de los valles interiores en desmedro, por ejemplo, de otros costeros.

El principio de integración, por tanto, resultó ser un aspecto sustancial para los lineamientos oficiales en materia de ordenamiento territorial. En el fondo, los nuevos e incipientes centros urbanos se constituyeron

\footnotetext{
${ }^{18}$ Es decir, aún aldeas comparables hoy en día a pueblos patagónicos ubicados en la costa de Aysén, caletas de pescadores o en la llamada carretera Austral. En dicha región, se habla de su constitución urbana para referirse a estos asentamientos que, al visitarlos, uno constata que no son más que pequeñas y frágiles aldeas que, como antaño, son sinónimo de progreso y modernidad. A modo de ejemplo, Caleta Tortel, Cochrane, Villa O'Higgins, Puerto Cisnes, Raúl Marín Balmaceda y La Junta.
}

en factores de cierta importancia para el desarrollo de las comunicaciones interregionales, contribuyendo con el tiempo a un arreglo -si bien modesto todavía- de los caminos antiguos y a la construcción de nuevas rutas, fundamentalmente para el transporte mular (Pinto Vallejos, 1976). Un contemporáneo criticaba el modelo de ocupación de espacio indicando que "Ios españoles han fundado sus ciudades..., pero muchas de ellas hubieran sido mejor colocadas sobre las riberas de los grandes ríos, para facilitarles el comercio. Este defecto es mucho más notorio en las nuevas fundaciones" (Molina, 2000: 312). Una excepción a esta regla lo constituyó Nueva Bilbao (1794), más tarde Ilamada Constitución, donde fue posible observar una ocupación del espacio de orientación autónoma, es decir, respondió a la necesidad de diversos pobladores para asentarse y afincarse en nuevos territorios (Acuña, 1944).

Por otra parte, en 1780 , en varios informes enviados a la Corona, ansiosa por tener información de lo que administraba, se indica una serie de pueblos para la provincia de Maule, entre otros Rauquén, Curato de Huenchullán, Peteroa, Lontué, Vichuquén y Paredones, todos los cuales destacan por una presencia muy elevada de españoles de ambos sexos (Solano, 1994). Esto permite relacionar, como ha quedado demostrado por especialistas en la materia, la estrecha vinculación entre los pueblos de indios y la futura ubicación de villas, de suerte que la mera presencia de un pueblo de indios siempre fue incentivo para situar allí alguna villa de españoles. Interesante es, a su vez, constatar que en la cartografía del siglo XVIII se indican una serie de lugares que suponen asentamientos humanos mezcla de pueblos de indios y de españoles (Lorenzo, 1987). En el mapa de la costa de Chile del Museo Naval de Madrid figuran bajos del Rapel y puerto de Natividad. En el plano de Reino de Chile en América Meridional, hecho por orden del virrey del Perú en 1793, se incluye al puerto de San Antonio y río Maipo; quebrada de Lora en el río Mataquito. Por último, en el mapa de América del Sur compuesto por Juan de la Cruz Cano, en 1775, resaltan los asentamientos de San Antonio, Bucalemu, Rapel y Topocalma.

En términos generales, por tanto, se estima que la práctica de la fundación de villas o 
aldeas en pleno siglo XVIII no logró materializar uno de sus objetivos esenciales: la modificación radical de la estructura territorial desintegrada existente en una etapa previa a los borbones. Lo diverso, lo distante, lo heterogéneo, la vastedad, persistió todavía de manera sólida.

Aun así, aquella relatividad no debe hacer perder de vista que su relevancia radica en que ellas -las villas- fueron la base urbana sobre la cual se desarrollaron durante el siglo XIX, a partir de la Independencia y de la consolidación del Estado nacional, las tendencias cada vez más vigorosas de la urbanización chilena (Geisse, 1977). Aquello que se Ilamó la valorización de lo urbano como eje de desarrollo territorial. El concepto ciudad, como medio de negocios y de poder, además de vincularse en vocero del progreso y de la Historia, continuó quedando todavía relegado a los espacios de concentración de población más importantes, como lo eran Santiago, Valparaíso, La Serena y Concepción. De hecho, en 1796 un comerciante talquino realizaba las gestiones para que Talca fuese declarada ciudad, ofreciendo pagar "100 pesos por una vez y su media anata que son 50 reales más un donativo de 500 ducados si fuere necesario para conseguir, junto al título de ciudad, los títulos de muy noble y leal" (Martínez Baeza, 1994: 84) ${ }^{19}$.

En este marco, a pesar de un alcance relativo en sus inicios, no debe mitigarse la importancia del proceso de racionalización espacial o política de poblaciones que se produjo en Chile en las postrimerías de la Colonia, proceso por lo demás común a toda América española (Martín Lou y Múscar, 1992 ${ }^{20}$. Tampoco, por cierto, inhibe el impulso reformista que para Santiago se produjo en el intercambio de ambos siglos; solo lo relativiza. De hecho, solo en Chile el cambio

19 Gabriel Guarda (1997) indica que de "las 260 fundaciones hispánicas (solo) 27 tuvieron el título de ciudad, 44 de villas, 34 fueron "plazas" y "lugares"; todas ellas de españoles, a las que hay que agregar 91 villas y reducciones de indígenas..." (Guarda, 1997: 68).

20 Dicen los autores (Martín Lou y Múscar, 1992): “Todos los espacios sudamericanos vieron surgir nuevas ciudades, sobre todo para ocupar espacios vacíos". Las fundaciones que se llevaron a cabo durante el en el panorama territorial entre el fin del siglo XVII y el término de la centuria siguiente sigue siendo notable. Hasta 1700 los poblados existentes se localizaban en una franja comprendida solo entre lo que hoy se conoce como el Norte Chico y la zona central, con un núcleo urbano de avanzada, Valdivia, al sur del Biobío, además de Concepción. Un siglo después, producto de aquella forma de racionalización, el panorama era notoriamente diferente, colaborando en la tendencia por generar un imaginario territorial más compacto, integrado y uniforme. Así se ha graficado en la Figura $\mathrm{N}^{\circ} 4$, la que debe ser comparada con la Figura $N^{\circ} 1$ para una mejor comprensión.

\section{Las ciudades como articuladoras de la representación del territorio nacional ${ }^{21}$}

Con el cambio de siglo, del XVIII al XIX, se asiste a una confirmación de lo que aquí se ha estado Ilamando la consolidación de la ciudad ilustrada en discurso verdadero, es decir, el momento en el cual la ciudad chilena se visualiza desde la interpretación moderna del territorio, tornándose clave en esta nueva representación espacial. El paisaje, un asunto cultural, ya no es el mismo, ahora le pertenece a la estructura imaginaria de la actitud ilustrada (Roger, 2007; Cosgrove, 2002), y en ese horizonte, la ciudad es un sujeto inevitablemente presencial. Se asiste, podría así llamarse, a la constancia del paisaje urbano.

siglo XVIII y hasta 1809 pueden ser agrupadas de la siguiente forma según los países en que se hallan actualmente: Venezuela, 115; Colombia, 25; Perú, 2; Bolivia, 1; Chile, 77; Argentina, 22; Paraguay, 18 y Uruguay, 13. A su vez, los índices de urbanización se colocaron entre $20 \%$ y $25 \%$ y se registró en toda América colonial un crecimiento general de la población: de 10,2; 11,4 y 11,7 millones de habitantes de 1570,1650 y 1700 , respectivamente, se pasó a 18,9 millones en 1800. De este modo, "la población de las grandes ciudades seguía en ascenso mientras que la población indígena comenzaba un lento crecimiento. Tanto las actividades económicas como el papel político asignado a otras ciudades, antes insignificantes, cambiarán el mapa colonial previo al siglo XVIII...". Para una mayor profundización del proceso de urbanización en América colonial, ver Solano (1990).

${ }^{21}$ El título es una adaptación de un notable artículo del filósofo argentino Biagni (1989). 
Por tanto, para el siglo XIX se debe entender la ciudad, lo urbano, como un pilar articulador y configurador de las políticas racionalizadoras que se desarrollaron sobre el territorio. Ellas, es decir, las ciudades (la ciudad como elemento ilustrado), fueron interpretadas y comprendidas como el ambiente donde el individuo mejor podía ejercer los talentos de la civilización. En cierta forma, la ciudad permitió incorporar al individuo al mundo de la razón (modernidad) frente a un mundo natural que aun siendo fuente de riqueza se vinculaba más bien con lo primitivo o lo atrasado. A su vez, lo urbano resultó ser un elemento vital para ordenar el territorio y fijar en él una trama coherente de relaciones, cuya armonía dependía en parte de anular los espacios vacíos y tender a la homologación simétrica de ellos. Como en Argentina, y otras latitudes americanas, aquellos espacios vacíos constituyeron verdaderas fronteras, en cierto modo obstáculos por resolver desde el poder (Hevilla, 1998; Zusman, 1999).

Lo anterior es clave para el siglo XIX chileno, cuyo inicio cultural es posible encon-
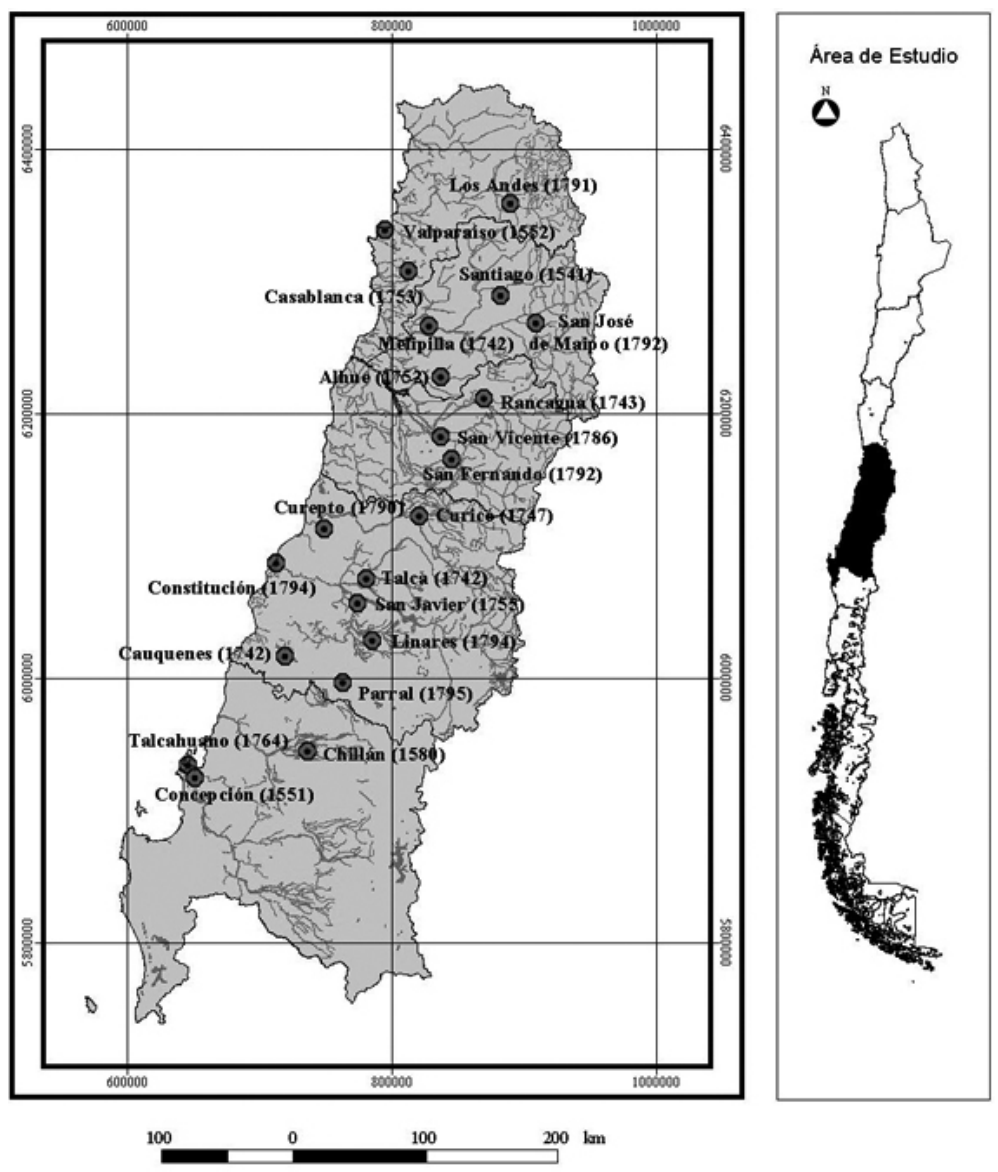
trarlo en la visión ilustrada de los borbones en pleno siglo XVIII, en tanto la ciudad no aparece tanto por crecimiento acumulativo de una aldea, sino por la interacción de unas aldeas sobre y con otras. Así, por ejemplo, lo percibía Benjamín Vicuña Mackenna, representante del liberalismo del siglo XIX, cuando establecía que para el siglo XVI, "Chile era entonces un desierto. No existían sino tres poblaciones que no pasaban de simples aldeas. Santiago, no tenía... sino quinientos vecinos, y La Serena solo contaba siete pobladores... Entre Santiago y el Biobío ¿qué recursos, que poblaciones intermedias había? Ninguna" (Vicuña Mackenna, 1939: 392). Ese panorama territorial, a sus ojos, resultaba ser un factor que evitaba el dinamismo que la civilización imponía al Estado. Refiriéndose en 1868 al asunto fronterizo con los indígenas del Biobío, expresaba que: "Nuestro deber primero es someter esa parte de la población a la parte central del territorio del Estado y de poner a cubierto las vidas e intereses de la población civilizada que está en su frontera, y como tal deber no puede ponerse en duda, es indispensable tener presente la extensión de esa frontera" (Vicuña Mackenna, 1939: 406).

Vicuña Mackenna (1939) vincula el ámbito citadino con lo civilizado, y en ese contexto Santiago, lo mismo que las otras capitales, debía liderar el camino del progreso: "Santiago ha sido siempre un modelo vivo de progreso para las demás ciudades de la República. ¿Ha progresado Santiago? Todas las capitales de provincia, los departamentos, las aldeas mismas, se han puesto en viaje hacia el adelanto. ¿Se estanca Santiago? Entonces todas las poblaciones se detienen y comienzan a podrirse... los pueblos en virtud de nuestra férrea centralización, están acostumbrados a mirarse como en un espejo en la capital; han copiado sus adoquines, sus avenidas plantadas de árboles, sus espaciosos caminos de cintura. Como patrón y modelo, el progreso de Santiago equivale al progreso universal de la comunidad..." (Vicuña Mackenna, 1939: 479).

Las palabras de Vicuña Mackenna (1939) reflejan huellas. Lo rural se opone a la nación, como pilar de un Estado que dibuja en la historia urbana la semblanza del progreso. De modo global, la ciudad simboliza el corazón del territorio nacional. El famoso Domin- go Faustino Sarmiento Ilega a sostener que la aldea francesa o chilena es la negación de Francia o Chile, y nadie quisiera aceptar ni sus costumbres, ni sus ideas, como una manifestación de la civilización nacional (Vicuña Mackenna, 1939).

Un territorio amplio, natural y disperso, por tanto, concentraba los ojos críticos de aquellos forjadores de la nación, autodefinidos como representantes de la modernidad. Refiriéndose a la Araucanía, el propio Vicuña Mackenna llega a ponderar negativamente el hecho que ese territorio dominado por el mundo indígena "se ha empequeñecido en territorio y en pobladores... es un hecho evidente la despoblación gradual y no interrumpida de la Araucanía" (Vicuña Mackenna, 1939: 409).

La ciudad, en este sentido, se transformó en un sujeto clave del modelo de ordenamiento del territorio que se impuso durante el siglo XIX. Es decir, fue una forma de racionalidad que tomó conciencia de sí, adquiriendo identidad y una estructura representacional e imaginaria para la comunidad, de modo que se tornó verdadera en la forma de percibir y modelar un espacio como el chileno. De hecho, se volvió indiscutible y tan cierta que, salvo los problemas que ellas han acarreado en el siglo XX (congestión, contaminación, entre otros) y que han puesto un manto de dudas en torno a ellas, en el XIX fue un sujeto necesario e ineludible de dominio y poder. Imposible oponerse a su figura.

En efecto, la ciudad fue un discurso de poder, fue un elemento que permitió orientar de mejor forma la actitud racional de la modernidad. Ella fue, en consecuencia, la cuna ideal donde la elite dirigente, constructora de una nación, pudo ejercer y desarrollar sus negocios. Ella una vez más concentraba la atención de las transacciones. El comercio, como lo indica Vicuña Mackenna (1939), en todas partes civiliza. Mirando al mundo indígena, sentencia: "Pasemos a la industria, a la agricultura, como medio de propaganda civilizadora. Pero de qué arte son capaces esos bárbaros, que solo saben amarrar sus lanzas y enfrenar sus caballos?" (Vicuña Mackenna, 1939: 420).

En las ciudades se concentraba, por tanto, aquel discurso que simbolizaba lo superior 
y el sentido del espacio controlado (en contraposición al salvaje, no controlado, rural o irracionalmente natural). En un mundo que buscaba homologar el territorio en una realidad u horizonte común, las ciudades jugaban un papel preponderante. Su consolidación era, en el fondo, una práctica estratégica que expresaba una cultura que se hacía global, característica del siglo XIX, donde se establecía y desarrollaba una relación de poder para con el mundo social circundante y, en este caso, para con el territorio. Lo que era Santiago para el resto del territorio, eran ciertos ambientes internos para el resto de Santiago. En efecto, en ella (la ciudad) existían áreas que integraban el patrimonio de la elite, reservas por lo general creadas con el propósito de satisfacer los requerimientos de una vida urbana tan sofisticada como elegante. Fundamentalmente, paseos donde era posible exponer un modo de vida, que no era sino una declaración categórica a favor de la distinción. Por tanto, sí cabe imaginar que la exclusividad traducida, por ejemplo, en la segregación social de los espacios, tuvo por objeto transformar una apreciación subjetiva (la superioridad oligárquica), en una realidad fáctica, concreta, palpable. Ella tenía, en definitiva, poderes capaces de objetivar sus propias interpretaciones (Vicuña Urrutia, 1996: 49).

Lo anterior, refleja que en buena parte la percepción moderna del territorio fue también el resultado de un proceso de objetivación de interpretaciones, que en cuanto sociales se transformaron en verdaderas. La teatralización o representación moderna del territorio tiene en parte que ver con aquella objetivación. La mirada moderna del territorio, con la ciudad y el ferrocarril como símbolos de una interpretación, fue el resultado de aquella puesta en escena (el mito que crea y consolida aquella mirada). En una nación donde todo estaba por hacer, interpretar el espacio era una meta y para ello se requerían agentes modernizantes. Uno de ellos, la ciudad. Ella dejó atrás los particularismos y buscó, en su afán de dominio, ejercer poder como identidad nacional.

Por cierto, la ciudad no fue el único sujeto que contribuyó a instalar un imaginario colectivo de un territorio más unificado y compacto. Durante el siglo XIX se desplegaron una serie de estrategias de poder que se sumaron a las desarrolladas en el XVIII (el control de los espacios vacíos, la búsqueda y acumulación de información, la exploración de nuevos territorios, la supremacía simbólica de la ciudad sobre lo rural). De las del siglo XIX se puede destacar la conformación de una historia nacional que diese sentido a sus habitantes, la materialización del telégrafo, del correo, el mejoramiento de caminos y puentes $y$, particularmente, la implementación del ferrocarril, todas iniciativas que colaboraron a configurar un espacio más unificado y homogéneo.

Por otra parte, el largo proceso de laicización de las instituciones y de la sociedad en general alentó y profundizó aquella unidad territorial requerida por la nación. Del mismo modo, el continuo progreso material en obras portuarias, caminos, en infraestructura en general, sumado a la incorporación de una serie de riquezas naturales al comercio nacional, aportó sustancialmente a la certeza de un territorio que se volvía cada vez más compacto e identificable en el imaginario colectivo.

En un trabajo, para el caso de México, en el marco de los estudios de nuevas identidades colectivas, Lemperiere (2003) hace un análisis semejante a este. Aun cuando se centra en materias religiosamente festivas (como lo hizo Paz para elaborar su "laberinto de la soledad"), establece que después de la desaparición del imperio español, las "múltiples identidades religiosas locales se oponían, por el simple hecho de seguir existiendo, al concepto homogeneizante e igualitario de la nación republicana liberal" (Lemperiere, 2003: 333). De allí que en México resultase mucho más complejo el proceso de llevar a la ciudad a los patrones de la oligarquía. En cierto modo, para usar las mismas palabras de aquel autor, la ciudad barroca compitió por largos años con la ciudad cívica. Por cierto, en Chile este proceso no se dio. Pero lo que sí sucedió, y que finalmente terminó imponiéndose también en México, fue la exigencia paulatina de una interpretación territorial que debía incorporar a las particularidades o, como ha sido llamado en una investigación más amplia, homologar las diversidades (Núñez, 2009): “... la nación como progreso era, por lo tanto, lógicamente, la asimilación de comunidades y pueblos más pequeños en otros mayores..." (Hobsbawm, 2000: 48). 
En definitiva, una dinámica urbana, como se dijo, que terminó por afianzar la cohesión que la nación requería para consolidarse. La ciudad, como el ferrocarril, el telégrafo $\mathrm{u}$ otros hitos de poder y dominio, por tanto, representó un símbolo que sirvió para identificar una concepción o interpretación del territorio específica (Geertz, 2000).

\section{Consideraciones finales}

Se han expresado en este relato dos aspectos centrales: 1) que la ciudad, en tanto acontecimiento discursivo, es un imaginario epocal, cuya representación, valor, interpretación, posición o punto de vista depende de su contexto histórico, por lo que no es posible otorgarle el rol de esencia, y 2) que su formación en discurso verdadero en la modernidad fue un proceso paulatino que conjugó miradas territoriales en tensión (del espacio vacío, diverso, fragmentado y heterogéneo al compacto, uniforme y homogéneo) y que la comprensión actual de la ciudad, en tanto forma de racionalidad, surgió principalmente del siglo XVIII y se afianzó, definitivamente, en el siguiente siglo. Ese fue el tiempo del surgimiento de lo que se ha llamado la constitución o interpretación moderna de la ciudad en Chile.

Desde ambas perspectivas, este texto es un problema del presente, ya que remite a lo que se es en la actualidad y cómo se convive en determinadas formas de conocimiento, poder o racionalidad, en este caso aún vigentes. En este ámbito, la ciudad, si bien es temporalmente muy antigua, no lo es tanto en su estructura imaginaria moderna, de acuerdo a la definición de modernidad formulada al inicio ${ }^{22}$.

Es decir, interesó preguntarse, a partir de la perspectiva histórica, qué es la ciudad hoy y qué representación de verdad continúa constituyendo hoy. Sin duda, todavía una certeza pero, por ejemplo, ya no brilla como durante el siglo XIX. El notable geógrafo

\footnotetext{
22 Se ha expresado en una investigación más amplia sobre la formación del imaginario moderno del territorio (Núñez, 2009): "El territorio se presentó en la modernidad como un 'texto'. El espacio y la naturaleza estaban allí, pero a la luz del protagonismo otorgado a la razón, aquel 'texto' fue siendo reinterpretado,
}

español Horacio Capel (2001) ha ilustrado respecto de este punto, al expresar que incluso la ciudad del XIX es posible de ser considerada una experiencia no comparable con el concepto de ciudad actual: "A partir de ese momento (siglo XIX), a la vez que la ciudad y lo urbano se convirtieron en objeto de reflexión, surgió la necesidad de inventar nuevas palabras que sirvieran para designar la nueva realidad espacial y los principios teóricos que permitieran controlar su desarroIlo. La "urbanización" en su doble sentido de proceso y resultado, así como las expresiones "suburbano" y "periurbano", aparecen precisamente para designar una nueva realidad" (Capel, 2001: 88).

La valorización de la ciudad, incluso en los inicios de la Ilustración, ha sido una realidad cambiante. Hoy la ciudad ya no genera el consenso de antaño, aunque no es tampoco una novedad que muchos bucólicos descarguen su ira contra ella. Ya en el siglo

de modo que lo que representó para unos hombres poco o nada tuvo que ver para otros. Es decir, el texto del territorio, como un rostro que varía con el tiempo, fue adquiriendo un significado distinto, de tal modo que la lectura de los hombres del siglo XVII era ya ilegible para los del XIX. Una suerte de hermenéutica del territorio. En el fondo, desde este punto de vista, la imagen del territorio le pertenece a cada cultura y es, por tanto, relativa. La representación del territorio se puede entender, por tanto, como un juego dual entre el lector y aquel territorio (el texto). La imagen del territorio se va objetivando en la conversación, en el lenguaje, en un proceso temporal, todo lo cual lleva al hombre a sentirse moderno en su relación con el territorio. ¿Qué hizo que los 'chilenos' se sintiesen 'modernos'? No fue tanto una creación o concepción de una realidad que 'era', por esencia, moderna. Más bien fue aquel acuerdo o uniformidad en el lenguaje que tomó un tiempo en solidificarse como imagen, lo que hizo que, a través de aquella objetivación, se adoptase una identidad modernizante (el 'mito', según Lévi-Strauss). Tanto en el siglo diecinueve como hoy se ha estimado que esa es una realidad sustancial o final, en la medida que existe consenso respecto de aquella identidad. Ese 'consenso' es lo que Foucault ha denominado acontecimiento discursivo que con el tiempo se torna 'verdadero'. Sin embargo, aquella 'realidad', como ha expresado Richard Rorty, viene a ser el espejo a través del cual proyectamos un sentido o una 'seguridad' para el ser. Es decir, el hombre se supo y sabe moderno a través de aquel espejo al que Ilamamos realidad". Muchos autores han colaborado a girar en esta perspectiva, entre otros: Nietzsche, Heidegger, Gadamer, Foucault, Lévi-Strauss y Francisco Varela, por nombrar algunos. 
XVIII incluso no era extraño escuchar voces críticas, ya que ante esta forma de secularización el mundo se apartaba de Dios (Capel, 2001). Sin embargo, se piensa que su emerger verdadero es todavía muy sólido y, que duda cabe, su lenguaje todavía es relevante en un ordenamiento territorial que la prioriza como sujeto regulador, que uniforma y le da sentido y racionalidad al espacio, del mismo modo, en eso no ha habido cambios, como se proyectó en los siglos XVIII y XIX.

Desde esta perspectiva, parece interesante posicionar a la ciudad como un referente cultural y un imaginario temporal. En otras palabras la ciudad no existe como valor superior, la ciudad es historia, es decir, la ciudad es punto de vista y perspectiva. Como ha expresado el propio Capel (2001): "Las dificultades para una definición de lo urbano derivan, ante todo, de la diversidad de situaciones sociales en que aparece y de la necesidad de introducir la perspectiva histórica en su caracterización" (Capel, 2001: 65).

Para concluir, en este texto el énfasis ha sido puesto en expresar que la ciudad en tanto acontecimiento discursivo ha sido, históricamente, una discontinuidad, es decir, no ha sido un proceso evolutivo donde en la actualidad se haya alcanzado un nivel superior de ciudad. Ella, por el contrario, en su representación actual es una forma cultural moderna y que, en ese contexto, desempeñó un papel y colaboró, junto a otras formas de racionalidad, en forjar una imagen del territorio particular, distinta e inconmensurable con otras antecedentes. La ciudad a partir del siglo XVIII se fraguó en una actitud hacia la vida muy diferente a la precedente. Esa actitud también fue territorial $y$, desde ese punto de vista, la ciudad -desde aquella interpretaciónse transformó en un sujeto relevante de aquel devenir. Es cierto, la ciudad como sujeto de poder y dominio fue y es relativa, pero no por ello menos verdadera.

\section{Referencias bibliográficas}

ACUÑA, C. Nacimiento de Nueva Bilbao. Santiago: inédito, 1944.

AMUNÁTEGUI, D. La sociedad de Santiago en el siglo XVII. Santiago: Dirección General de Prisiones, 1937.
BAYON, D. Sociedad y arquitectura colonial sudamericana. Barcelona: Editorial G. Gilli S. A., 1974.

BIAGNI, H. E. Las ciudades como clave de lo nacional. En: PESET, J. L. (coord.). Ciencia, Vida y Espacio en Iberoamérica. Madrid: Consejo Superior de Investigaciones Científicas, 1989, p. 579-592.

CAPEL, H. Dibujar el mundo. Borges, la ciudad y la geografía del siglo XXI. Barcelona: Serbal, 2001.

CÉSPEDES DEL CASTILLO, G. La organización del espacio físico y social. En: CASTILLERO CALVO, A. Consolidación del orden colonial. Historia General de América latina. Vol. II. París: Editorial Trotta-Unesco, 2000, p. 57-74.

COBOS, M. T. La división político administrativa de Chile, 1541-1811. Valparaíso: Universidad Católica de Valparaíso, Serie Monografías Históricas 3, 1989.

COSGROVE, D. Observando la naturaleza: el paisaje y el sentido europeo de la vista. Boletín de la A.G.E., 2002, № 34, p. 63-89.

CHUECA, F. Breve historia del urbanismo. Madrid: Alianza, 1997.

FOUCAULT, M. Obras esenciales: estética, ética y hermenéutica. Vol. 3. Barcelona: Paidós, 1999.

FOUCAULT, M. Saber y verdad. Madrid: Ediciones de la Piqueta, Serie Genealogía del Poder, 1991.

GAY, C. Historia física y política de Chile: según documentos adquiridos en esta República durante doce años de residencia en ella. Vol. 2. París: Imprenta de Fain y Thunot, 1840.

GEERTZ, C. La interpretación de las culturas. Barcelona: Gedisa, 2000.

GEISSE, G. Origen y evolución del sistema urbano nacional. EURE, 1977, vol. V, $N^{\circ} 14$, p. $37-46$.

GÓNGORA, M. Estratificación urbana en Chile. Siglos XVI, XVII y primera mitad del 
XVIII. Wisconsin: University of WisconsinMilkwaukee, Center for Latin American Studies, 1971.

GÓNGORA, M. Encomenderos y estancieros. Estudio acerca de la constitución social aristocrática de Chile después de la Conquista. 1560-1660. Santiago: Universidad de Chile, Editorial Universitaria, 1970.

GÓNGORA, M. Origen de los inquilinos de Chile central. Santiago: Universitaria, 1960.

GÓNGORA, M. Evolución de la propiedad rural en el valle de Puangue. Santiago: Universidad de Chile, 1955.

GONZÁLEZ, I. Ingeniería española en UItramar. Madrid: Ministerio de Obras Públicas y Transportes, 1992.

GUARDA, G. Historia urbana del Reino de Chile. Santiago: Ed. Andrés Bello, 1978.

GUARDA, G. La sociedad en Chile austral antes de la colonización alemana. 1645 1850. Santiago: Ed. Andrés Bello, 1979.

GUARDA, G. El arquitecto de la Moneda. Joaquín Toesca. Una imagen del imperio español en América. 1752- 1799. Santiago: Ediciones Universidad Católica de Chile, 1997.

HEVILLA, C. El estudio de la frontera en América. Una aproximación bibliográfica. $B i-$ blio 3W. Revista Bibliográfica de Geográfica y Ciencias Sociales, 1998, No 125. Disponible en Internet: http://www.ub.es/geocrit/ b3w-125.htm

HOBSBAWM, E. J. Naciones y nacionalismo desde 1780. Barcelona: Crítica, 2000.

JARA, A. Fuentes para la historia del trabajo en el Reino de Chile. Legislación. Tomo I. Santiago: Universidad de Chile, Editorial Universitaria, 1965.

LEMPERIERE, A. De la república corporativa a la nación moderna. México (18211860). En: GUERRA, F. X. y ANNINO, A. (coords.). Inventando la nación iberoamérica. Siglo XIX. Ciudad de México: Fondo Cultura Económica, 2003, p. 316-346.
LÓPEZ DE VELASCO, J. Geografía y descripción universal de las indias (1571-1574). Relaciones de Chile. Tomo XXVII. Santiago: Imprenta Elzeviriana, Colección de historiadores de Chile, 1901.

LORENZO, S. Concepto y funciones de las villas chilenas del siglo XVIII. Historia, 1987, No 22, p. 91-105.

LORENZO, S. y URBINA, R. La política de poblaciones en Chile durante el siglo XVIII. Quillota: Ed. El Observador, 1978.

MARTíN LOU, M. A. y MÚSCAR, E. Proceso de urbanización en América del Sur. Modelos de ocupación del espacio. Madrid: Mapfre, 1992.

MARTÍNEZ BAEZA, S. (comp.). Epistolario de Don Nicolás de la Cruz y Bahamonde Primer conde de Maule. Santiago: Dirección de Bibliotecas, Archivos y Museos, Colección de Fuentes para el estudio de la Colonia, 1994.

MELLAFE, R. Las primeras crisis coloniales, formas de asentamiento y origen de la sociedad chilena: siglos XVI y XVII. Estudios, $1975, N^{\circ} 7$, p. 117-135.

MELLAFE, R. El latifundio y poder rural en Chile en los siglos XVII y XVIII. Cuadernos de Historia, 1981, № 1, p. 87-108.

MUÑOZ, M. D. Transformaciones urbanas de las ciudades chilenas del siglo XVIII. Tesis doctoral. Madrid: Escuela Técnica Superior de Arquitectura, Universidad Politécnica de Madrid, inédito, España, 2009.

MEDINA, J. T. Catálogo breve de la Biblioteca Americana. Manuscritos. Tomo I. Documentos inéditos para la historia de Chile. 1535-1720. Santiago: Imprenta Universitaria, 1928.

MOLINA, J. I. Compendio de la historia civil del Reyno de Chile. Santiago: Pehuén editores, 2000.

NIETZSCHE, F. Consideraciones intempestivas. Madrid: Alianza, 1988.

NúÑEZ, A. Formación y consolidación de la representación moderna del territorio 
en Chile 1700-1900. Tesis doctoral. Santiago: Instituto de Historia, Facultad de Historia, Geografía y Ciencia Política, Pontificia Universidad Católica de Chile, Chile, 2009.

PINTO VALLEJOS, S. Vías y medios de comunicación en Chile durante el siglo XVIII: el camino de Santiago a Valparaíso y su tráfico. Santiago: Ed. Departamento de Estudios Humanísticos, 1976.

PIRENNE, H. Las ciudades de la Edad Media. Madrid: Alianza Editorial, 1980.

DE RAMÓN, A. Historia urbana. Una metodología aplicada. Buenos Aires: Clacso, Ediciones Siap, 1978.

DE RAMÓN, A. Gravitación histórica de Santiago, siglos XVI-XIX. Revista Universitaria, 1990, No 31, p. 31-35.

ROGER, A. Breve tratado del paisaje. Madrid: Edición de Javier Maderuelo, Biblioteca Nueva, Colección Paisaje y Teoría, 2007.

ROMERO, J. L. La ciudad occidental: culturas urbanas en Europa y América. Buenos Aires: Siglo XXI, 2009.

SALAZAR, G. Labradores, peones y proletarios. Formación y crisis de la sociedad popular chilena del siglo XIX. Santiago: Ediciones SUR, 1985.

SOLANO, F. Relaciones económicas del Reino de Chile. Madrid: Consejo Superior de Investigaciones Científicas, 1994.

SOLANO, F. y CERRILLOS, M. L. (Coords.). Historia urbana de Iberoamérica. La ciudad barroca. Tomo II. Madrid: Testimonio Ediciones, 1990.

SOLANO, F. Ciudades hispanoamericanas y pueblos de indios. Madrid: Biblioteca de Historia de América, CSIC, 1990.

TÉLLEZ, E. Los Pehuenches primitivos. Tesis grado Magíster en Historia con mención en etnohistoria. Santiago: Escuela de Historia, Facultad de Filosofía y Humanidades, Universidad de Chile, Chile, 1990.
TORIBIO MEDINA, J. Catálogo breve de la Biblioteca Americana. Manuscritos, Tomo I. Documentos inéditos para la historia de Chile. 1535-1720. Santiago: Imprenta Universitaria, 1928.

TREBBI DEL TREVIGIANO, R. DesarroIlo y tipología de los conjuntos rurales en la zona central de Chile siglos XVI-XIX. Santiago: Eds. Nueva Universidad, 1980.

TSCHEREBILO, S. Estructuración y funciones de las aldeas y espacios urbanos intermedios en un contexto agrícola. Tesis grado Licenciatura en Historia. Santiago: Instituto de Historia, Facultad de Historia, Geografía y Ciencia Política, Pontificia Universidad Católica de Chile, Chile, 1976.

UGARTE PALMA, R. Los Pehuenches y su espacio. Tesis grado Licenciatura en Historia. Santiago: Instituto de Historia, Facultad de Historia, Geografía y Ciencia Política, Pontificia Universidad Católica de Chile, Chile, 1996.

VARELA, F. Conocer. Las ciencias cognitivas: tendencias y perspectivas. Cartografía de las ideas actuales. Barcelona: Gedisa editorial, 2002.

VICUÑA MACKENNA, B. Discursos parlamentarios I y II. Cámara de Diputados. Santiago: Universidad de Chile, obras completas vol. XII, 1939.

VICUÑA URRUTIA, M. El París americano. La oligarquía chilena como actor urbano en el siglo XIX. Santiago: Universidad Finis Terrae, 1996.

VILLALOBOS, S. Historia de Chile. Tomo 3. Santiago: Editorial Universitaria, 1985.

VILLALOBOS, S. y RODRÍGUEZ, C. El espacio rural Longaví-Ñuble 1737. Cuadernos de Historia, 1997, № 17, p. 105-144.

ZUSMAN, P. Representaciones, imaginarios y conceptos en torno a la producción material de fronteras. Biblio $3 W$. Revista Bibliográfica de Geográfica y Ciencias Sociales, 1999, No 149. Disponible en Internet: http:// www.ub.es/geocrit/b3w-149.htm 